\title{
WHO guide to good prescribing is 25 years old: quo vadis?
}

\author{
J. Tichelaar ${ }^{1,2}$ (I) $\cdot$ M. C. Richir ${ }^{1,2} \cdot$ S. Garner ${ }^{3} \cdot$ H. Hogerzeil ${ }^{4}$ Th. P. G. M. de Vries ${ }^{1,2}$
}

Received: 9 October 2019 / Accepted: 22 December 2019 / Published online: 14 January 2020

(C) The Author(s) 2020

\begin{abstract}
Introduction Twenty-five years ago, the World Health Organization (WHO) published the Guide to Good Prescribing (GGP), followed by the accompanying Teacher's Guide to Good Prescribing (TGGP). The GGP is based on a normative 6-step model for therapeutic reasoning and prescribing, and provides a six-step guide for students to the process of rational prescribing.

Method We reviewed the need to update both WHO publications by evaluating their use and impact, including new (theoretical) insights and demands. Based on information from literature, Internet, and other (personal) sources, we draw the following conclusions. Results 1. An update of the GGP and TGGP, both in terms of content and form, is necessary because of the current need for these tools (irrational medicine use and unavailability of medicines), the lack of similar documents, and the lack of connection with recent developments, such as Internet and modern education; 2. The basic (6-step) model of the GGP is effective in terms of rational prescribing in the undergraduate situation and is still consistent with current theories about (context) learning, clinical decision-making, and clinical practice; 3. The dissemination and introduction of the GGP and TGGP in education has been successful so far, but is still not optimal because of lack of support and cooperation.

Conclusions On the basis of the evaluation results, a plan for the revision of the GGP and TGGP is presented.
\end{abstract}

Keywords Guide to good prescribing $\cdot$ WHO 6 step $\cdot$ Rational prescribing $\cdot$ Pharmacotherapy $\cdot$ Education $\cdot$ Clinical pharmacology

\section{Introduction}

\section{(Quo vadis) Where are you going?}

Due to a perceived need for improving prescribing practices, the World Health Organization (WHO) published the Guide to Good Prescribing (GGP) in 1994, followed by the

Electronic supplementary material The online version of this article (https://doi.org/10.1007/s00228-019-02823-w) contains supplementary material, which is available to authorized users.

J. Tichelaar

j.tichelaar@amsterdamumc.nl

1 Research and Expertise Center In Pharmacotherapy Education (RECIPE), Amsterdam, the Netherlands

2 Department of Internal Medicine, Section Pharmacotherapy, Amsterdam UMC, location VU University Medical Center, De Boelelaan 1117 (ZH 4A48), 1081 HV Amsterdam, the Netherlands

3 WHO, Health Technologies and Pharmaceuticals Programme, WHO Regional Office for Europe, Copenhagen, Denmark

4 Department of Health Sciences Global Health, University Medical Centre Groningen, University of Groningen, Groningen, the Netherlands accompanying Teacher's Guide to Good Prescribing (TGGP) in 2001 [1, 2]. The GGP is based on a 6-step model for rational prescribing (Table 1) and is primarily intended for undergraduate students and their teachers. A more detailed description and history of origin of both the original GGP and TGGP can be found in box 1 as part of the online supplementary materials of this article [3]. Both the GGP and TGGP can be downloaded for free from the WHO website and the GGP has been translated into 24 languages or local editions (Table 2).

Since its publication in 1994, more than 100 original articles have referred to the GGP in a wide range of medical journals, ranging from geriatrics, primary health care, internal medicine, psychiatry, education to (clinical) pharmacology and pharmacy. The latter category, namely, (clinical) pharmacology and pharmacy, accounts for more than half of the referring publications to the GGP.

Today, Good Prescribing guidance remains as necessary as ever. In 2018, the WHO launched the Global Action Plan (www.who.int/sdg/global-action-plan) which represents a historic commitment by global health and development agencies to advance collective action and accelerate progress towards the health-related targets of the 2030 Agenda for Sustainable Development. Sustainable development goal 
Table 1 WHO 6-step model for rational prescribing [1]

\begin{tabular}{ll}
\hline Step 1 & Define the patient's problem \\
Step 2 & Specify the therapeutic objective \\
Step 3a & Choose your standard treatment (p-drug) \\
Step 3b & Verify the suitability of your treatment (p-drug) \\
Step 4 & Start treatment \\
Step 5 & Give information, instructions, and warnings \\
Step 6 & Monitor (and stop?) treatment \\
\hline
\end{tabular}

Target 3.8 is the achievement of universal health coverage (UHC), including financial risk protection, access to quality essential health care services, and access to safe, effective, quality, and affordable essential medicines and vaccines for all.

Central to access to safe and effective medicines is ensuring that those prescribing the medicines have clear objectives and can engage with their patients to obtain appropriate information and hear their experience of their disease and treatment. Prescribers can be a physician in a tertiary care center or pharmacists and nurses in the frontline of primary care. Furthermore the development of mobile technology now provides an unprecedented platform for both guidelines and training modules.

A group of experts from the WHO and Amsterdam University Medical Centre recently discussed the need to update the GGP and TGGP. They concluded that these valuable guides should be updated, especially because of the lack of alternative guidelines and the increasing global need for rational medicine use [4]. They advised that the current use and impact of these guides, including new (theoretical) insights and demands, be evaluated first.

In this paper, we present the results of this evaluation, which was based on a thorough literature and internet search, and the use of other (personal) sources. It focused on the impact of the GGP and TGGP on teaching and prescribing skills and relevant new developments in the field. We close by

Table 2 Translations and local editions of the WHO Guide to Good Prescribing 1994-1999 (WHO Geneva)

\begin{tabular}{ll}
\hline Albanian & Indonesian \\
Arabic & Italian \\
Bengali & Japanese \\
Bosnian & Mongolian \\
Catalan & Portuguese \\
Chinese & Romanian \\
Dutch & Russian \\
English & Serbian \\
Farsi & Slovakian \\
French & Spanish \\
French/Algerian & Turkish \\
German & Vietnamese \\
\hline
\end{tabular}

describing a project to determine what should be changed and how appropriate changes should be made.

\section{Impact on prescribing skills}

Before the GGP was published, two randomized controlled trials had shown that the problem-based teaching of the 6step method had a positive effect on prescribing skills and knowledge. Medical students from seven universities from all over the world were not only able to solve clinical problems that had been used during medical training (retention effect), but could also use these skills and knowledge to solve other clinical problems (transfer effect) $[5,6]$. Thereafter multiple comparative studies (three randomized controlled trials, three non-randomized comparative control, and two beforeand-after studies) reported similar effects of the 6-step method on various aspects of rational prescribing by both medical students and GPs in a wide range of countries [7]. Interestingly these positive results were also seen before and after a 3-day course for nurses and paramedical prescribers in South Africa when measuring WHO antibiotic prescribing indicators in daily practice (MSc-dissertation; Hannelie Meyer (med), School of Pharmacy Medunsa, South Africa, 1998). In a systematic review of educational interventions to improve rational prescribing, published between 1990 and 2013, Kamarudin and co-workers found that the WHO 6step method had the largest body of supportive evidence as method to improve rational prescribing [7]. Ross and coworkers had reported similar findings in a systematic review about 5 years earlier [8].

\section{Impact on teaching}

In the realization that the publication of the GGP would not be effective in just spreading the word about rational prescribing, the WHO started to support problem-based pharmacotherapy training courses for teachers. They selected and paid for clinical pharmacology/pharmacotherapy teachers from all WHO regions to attend 2 -week courses, the first six of which were held at the WHO Collaborating Centre at the University of Groningen in the Netherlands (1995-2000). After attending these courses, participants were expected to organize similar national or regional courses. At least seven such courses were organized the period 1996-2001 in three different WHO Regions (South Africa, Argentina, Indonesia and the Philippines). In the WHO Eastern Mediterranean Region, several advocacy training courses were held for university teachers in Egypt, Jordan, the Gulf States, the Islamic Republic of Iran, and Iraq. The WHO also provided support for the translation of the GGP. There are currently 24 
translations or local editions, at that time (2001) making the GGP the second most-translated WHO publication (Table 1).

In 2005, Smith et al. evaluated the educational outcomes of these training courses [9]. All 245 participants had been asked to document their teaching practices before and after attending the course. The number of participants who used a problembased approach to teach evidence-based prescribing increased from $17 \%$ before to $80 \%$ after the course. Moreover, $75.5 \%$ of the attendants had been able to make changes to teaching methods and/or curricula, $92.6 \%$ of which are still in force. A number of participants have organized courses on CPT education in their own region.

As shown in a recent publication, $14 \%$ of European medical schools use the WHO 6-step model in their curricula [10]. Of this $14 \%$, a third (36\%) are Dutch (eight) and Belgian (one) [11]. The high use of the WHO 6-step in the Netherlands reflects the pioneering role the country has had in the use and evaluation of the GGP. For example, the Dutch Society for Clinical Pharmacology and Biopharmacy organizes an annual "Teach the Teachers" course based on the WHO 6-step program as part of postgraduate training in CPT. Moreover, Dutch and Flemish universities work together in the education working group of the Dutch Society for Clinical Pharmacology and Biopharmacy, which advocates the use of a web-based prescribing learning program (P-scribe) and which has developed a compulsory examination for finalyear medical students to assess prescribing. This so-called "prescribing license" examination was introduced in three Dutch medical schools in 2014 [12, 13] and will gradually be implemented in the other Dutch and Flemish universities. All UK medical schools have long assessed the prescribing skills of final-year students. Collaboration between the UK Medical Schools Council and British Pharmacological Society led to the development of the online UK Prescribing Safety Assessment (PSA) based on a similar (10-step) approach $[14,15]$. A report described the delivery of the PSA to all UK final-year medical students in 2016. A total of 7343 final-year medical students in all $31 \mathrm{UK}$ medical schools sat the PSA. The overall pass rate was $95 \%$ with the pass rates for the individual papers ranging from 93 to $97 \%$ [15].

In 2006, Smith et al. reported on the development and evaluation of a web-based interactive prescribing curriculum for Australian senior medical students, based on the GGP [16]. The project was initiated by the National Prescribing Service to improve the quality of prescribing education. In 2004, 9 of 11 Australian medical schools used the curriculum. In Canada, an e-learning program combined with interprofessional coteaching (physician-pharmacist) based on the GGP process of rational prescribing has been developed to support effective prescribing in the family medicine residency program [17]. In some medical schools in Spain, a mobile so-called p-drug app for medical students and their teachers has been in use since 2009. This allows teachers to correct and grade students as they choose their p-drugs and solve patient problems [18]. Lastly, Turkey has developed a postgraduate training course (based on the GGP) to improve the rational pharmacotherapy planning behavior of general practitioners [19]. Undoubtedly there are many more countries where the GGP or a method derived from it is used. Since these initiatives have not been published (literature or internet), it is unfortunately difficult to say anything about these local activities and developments. It is therefore one of the goals of this publication and of the first phase (see chapter "revision project") to get in touch with users around the world and learn more about their activities.

\section{Related developments}

In the past 25 years, several developments have occurred in relation to the GGP and the TGGP and to the teaching of the 6step method.

\section{Medical and prescriber education}

Before the publication of the GGP, sequential learning was the main teaching method in medical education: first gaining and then applying knowledge. In the 1980s, problem-based teaching was gradually introduced as a way to help students acquire knowledge by solving problems; later, this approach was used to help students acquire both knowledge and cognitive skills (clinical and therapeutic reasoning). Nowadays, based on further research in cognitive psychology and learning processes, context learning is advocated as the most effective teaching method.

Context learning is defined as learning in a setting that is similar to that of the future profession [20]. For medical students, this is a clinical setting. Context learning can be implemented in various ways, i.e., from written patient cases or role play sessions to real clinical practice. For example, student-run clinics are a new educational concept to prepare medical students for their role as prescriber [21]. The clinics have been shown to provide the most realistic setting for context-based learning while at the same time giving students early clinical experience with maximum responsibility for patient care [22]. As shown recently by Schutte et al., a student-run clinic focused on pharmacotherapy education is feasible, valuable, and offers students the opportunity to learn in a real interprofessional setting [23]. Furthermore, students show a high level of intrinsic motivation to participate in these clinics and perceive an improvement in their pharmacotherapy competence [24]. Current knowledge about, and the relationship between, context learning, therapeutic decisionmaking, and clinical practice (6-step approach), is summarized in Fig. 1. 
Fig. 1 Current understanding of how students and junior doctors learn to prescribe medicines can be summarized in a composite model based on three separate models, namely, the normative rational pharmacotherapeutic process in clinical practice (WHO 6-step), therapeutic reasoning (in experienced and non-experienced prescribers), and contextual learning [25]. See http://dare. ubvu.vu.nl/handle/1871/54827 for more detailed information

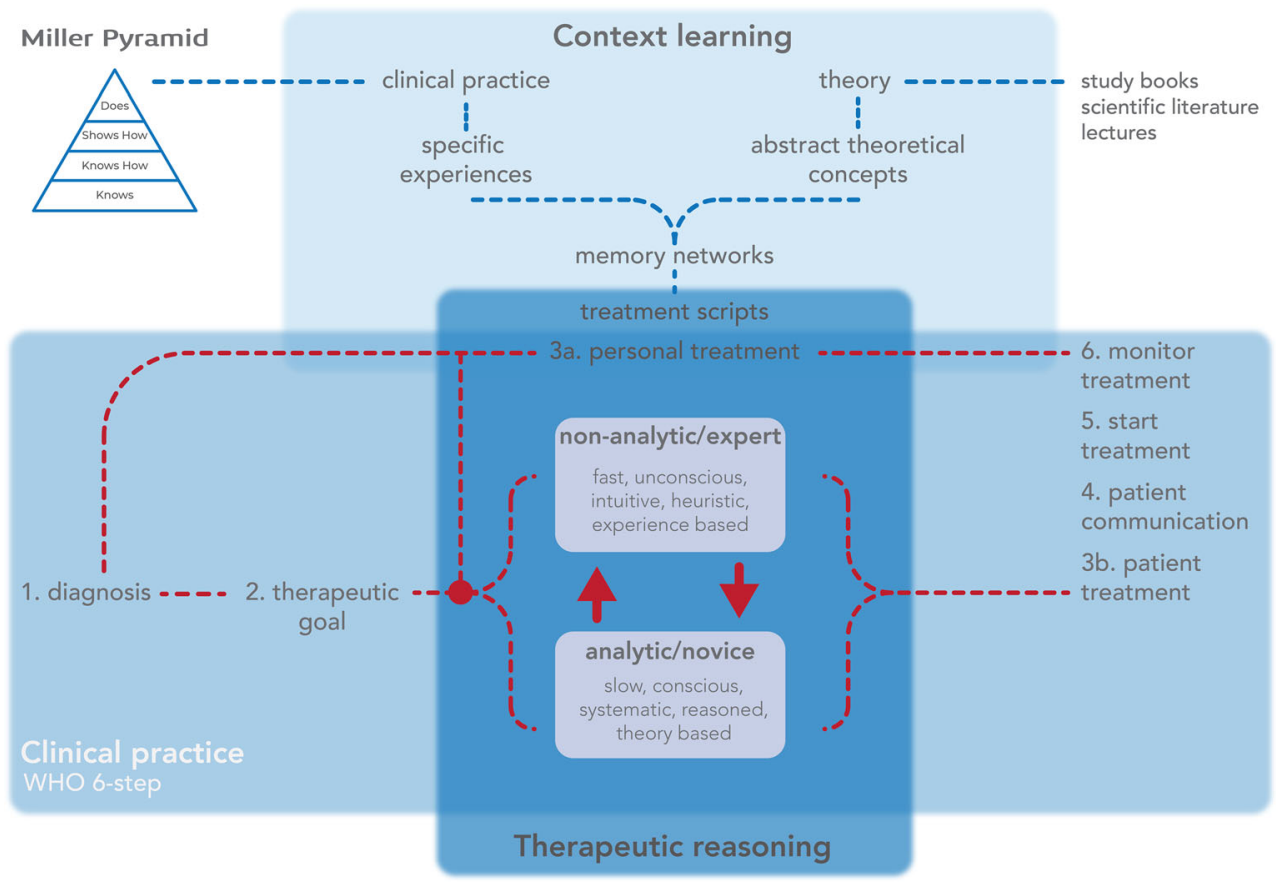

\section{Internet/digital support systems}

Internet and mobile technology (smart phones, personal computers) has enabled current and future prescribers in both HIC (high-income countries) and LMIC countries to access vast amounts of pharmacotherapy-related information. Moreover, tools, such as treatment guidelines, medicine-medicine interaction checkers, and clinical decision support systems, have become indispensable to prescribing practice. These digital prescribing tools are of course a huge advance, but the problem of "alert fatigue," [26] where prescribers ignore much of the interaction alerts even if they are clinically relevant, shows that digital tools can never be the only solution in terms of medication safety. Therefore digital prescribing tools are an increasingly important guide on the side to the process of prescribing, but can never be a replacement for rational therapeutic reasoning. Moreover, the digital revolution in prescribing shifts the challenge of teaching and learning good prescribing towards the selection and critical appraisal of information, rather than merely gaining factual knowledge. The Internet also makes interactive (distance) education possible. Indeed, it was recently shown that online digital learning resources are important assets to many prescribing curricula, and that they are effective in teaching the required knowledge, skills, and attitudes [27]. The open sharing of these resources between universities is currently being investigated as means to harmonize and modernize prescribing education [28]. The GGP and TGGP should use the internet potential for widespread dissemination. Finally, it should not be forgotten that digitization not only supports health professionals, but that patients are increasingly making use of it.

\section{Patient care/shared decision-making}

Patient care has evolved in many ways. An important development is the role of the patient, especially with regard to increasing patient assertiveness, knowledge, and patient responsibility for their own health. Shared decision-making (SDM) has become increasingly important in patient care. Instead of clinicians making therapeutic decisions on behalf of patients, clinicians and patients share the best available evidence and possibilities about a specific treatment to reach a shared decision [29].

\section{Other prescribers}

Until recently, in most countries, only medical practitioners and dentists were legally licensed to prescribe medicines. Nowadays, more professional groups, such as nurse practitioners, physician assistants, and even pharmacists, are authorized to prescribe (some) medicines in several countries. Furthermore, in LMIC, it is common practice that paramedics are in the front line of medical care. There is no reason to suggest that the logic of GGP between medics and other professionals is different, but their experiences might differ and be content specific.

\section{Medicine use}

The need to promote the rational use of medicines is perhaps greater now than it was 20 years ago. Evidence-based guidelines are now an accepted part of prescribing culture, and health technology assessment often defines what is available 
in the benefit packages and available to prescribers. Although government funding and health insurance are increasing in many low- and medium-income countries (LMIC's), access to affordable, quality-assured, safe, and effective medicines continues to be a major challenge. It is becoming one in wealthy countries as well, as a result of the increasing cost of medicines and medical appliances [30]. In addition, the increasing problem of polypharmacy, in particular in HIC's and MIC's, is leading to a growing awareness of the problem and implementation of deprescribing practices.

\section{EACPT/IUPHAR}

Last but not least, over the past 25 years, the European Association for Clinical Pharmacology and Therapeutics (EACPT) has evolved to become a valuable organization for teaching CPT [31]. The Association's biannual conferences hold two symposia on education, and the Association supports an active working group on CPT teaching. Two summer schools on CPT Education have been held recently (2012 Amsterdam and 2018 Birmingham). Furthermore, the EACPT has funded several international studies on education since 2015 [10, 28, 32, 33]. This support has resulted in an impressive network of universities and active teachers in Europe (and beyond), a network which could also function as a way to disseminate the GGP and TGGP. A similar development occurred in the International Union of Pharmacology and Clinical Pharmacology (IUPHAR).

\section{Discussion, conclusions}

The aim of the evaluation was to give direction to the envisaged updating of the GGP and TGGP and was based on information from the Internet and several other (personal) sources. This evaluation is not complete; several local and unpublished activities and developments may have been missed, in particular, with respect to LMIC. However, despite this, a number of (provisional) conclusions can still be drawn:

1. An update of the GGP and TGGP, both in terms of content and form, is necessary after 25 years because of the current need for these tools (irrational medicine use and unavailability of medicines remain a problem), the lack of similar documents, the lack of relevance with regard to recent developments, and the possible non-optimal treatment suggestions in the patient cases of both documents that are out of date and do not reflect the prescribing options available.

2. The basic (6-step) model of the GGP is effective in terms of rational prescribing in the undergraduate situation. It is basically consistent with theories about (context) learning, clinical decision-making, and clinical practice. However, all steps need to be critically re-appraised with respect to their appropriateness for (teaching) rational prescribing. An important focus for the revision will be the choice of medicine (step 3a and b). Experienced doctors have developed their own sets of p-drugs (treatment script or evoked-set), consistent with clinical decision-making theories $[34,35]$. What is not known is how these treatment scripts or sets are established [25]. Unfortunately, irrational prescribing still exists despite these scripts and the availability of treatment guidelines. Other focus points will be the choice of ineffective and expensive forms of drug administration, such as injections, and shared decision-making, including the patient's role in his/her health.

3. The dissemination and introduction of the GGP and TGGP in education has been successful so far, but is still not optimal. Lack of support and cooperation are possible causes, as reflected by the positive effect of efforts to overcome these barriers in countries such as Australia, the UK, and the Netherlands with their local "ambassadors."

Bearing these findings in mind, the GGP and TGGP should be revised in the broadest possible sense. This objective means that not only should their content and form be revised, but also their dissemination and use in teaching and assessment should be optimized (both in under- and postgraduate setting and in continuing medical education). This aim requires more organization, collaboration, and coordination by "ambassadors" at local, national, and international levels. Furthermore, the impact of the GGP and TGGP on prescribing skills and behavior should be evaluated. It goes without saying that the GGP and TGGP and the accompanying teaching materials and methods should be easily adaptable to local needs and possibilities, in particular with respect to LMIC's.

\section{Revision project}

On the basis of the evaluation results, we have developed a plan for the revision of the GGP and TGGP. It consists of three phases, which partly overlap.

In the first phase (2019/2020), the aim is to define the ultimate goals of the GGP and TGGP and to determine what should be changed (and what not) with respect to their content and form. At the same time, we will review what other teaching materials and prescribing guides exists, and what can be learned from them.

We will perform an online cloud-based questionnaire among selected teachers, (postgraduate) students, and prescribers from HIC and LMIC in all 6 WHO regions. We 
invite readers of this article to participate via www. guidetogoodprescribing.org. Where necessary, several questionnaire rounds will be performed in order to reach consensus. This approach will also make it possible to identify capable revisers for phase 2. Furthermore, preparations will be made for phase 2 .

The aim of the second phase (2020/2021) is the actual revision of the GGP and TGGP. The methodology to be used has still to be developed. A contemporary online version will also be developed.

In the third phase (2021/2023), the GGP and TGGP will be disseminated, evaluated, and optimized for use. The impact of these guides on prescribing skills will be evaluated. All reviewers and writers will be closely involved in this phase. It is still too early to provide detailed plans for this phase yet.

The project will be performed by RECIPE (Research and Expertise Center in Pharmacotherapy Education), Department of Internal Medicine, Amsterdam UMC, location VU University Medical Center, in close collaboration with the WHO. The project leaders are Ass. Prof. Jelle Tichelaar, Ass. Prof. Milan Richir (both Amsterdam UMC), and Dr. Sarah Garner (WHO Regional Office for Europe). Till June 2019, Dr. Sarah Garner worked at the WHO Headquarters in Geneva; from June 2019, her new position is Acting Program Manager.

Health Technologies and Pharmaceuticals, Division of Health Systems, and Public Health at the WHO Regional Office for Europe. Relevant stakeholders such as EACPT and IUPHAR will be asked to advise or support the project, for example, in committees, or advisory boards or by contributing to the revision. More information: website WHO GGP or RECIPE: www.guidetogoodprescribing.org-www. recipeamsterdam.com

Acknowledgments We thank the members of the Education Working Groups of EACPT and IUPHAR for their valuable comments on and contributions to the draft version of this paper. We thank the authors of the first editions for their consent in the revision of the GGP and TGGP and their valuable advises. We also thank Robert Summers for his valuable comments and Chiel Bakkum for his help with both the part on internet/digital support systems and the development of the website.

Open Access This article is licensed under a Creative Commons Attribution 4.0 International License, which permits use, sharing, adaptation, distribution and reproduction in any medium or format, as long as you give appropriate credit to the original author(s) and the source, provide a link to the Creative Commons licence, and indicate if changes were made. The images or other third party material in this article are included in the article's Creative Commons licence, unless indicated otherwise in a credit line to the material. If material is not included in the article's Creative Commons licence and your intended use is not permitted by statutory regulation or exceeds the permitted use, you will need to obtain permission directly from the copyright holder. To view a copy of this licence, visit http://creativecommons.org/licenses/by/4.0/.

\section{References}

1. De Vries TP, Henning RH, Hogerzeil HVet al (1994) Guide to good prescribing. World Health Organisation, Geneva

2. Hogerzeil HV, Barnes KI, Henning RH, Kocabasoglu YE, Moller H, Smith AJ, Summers RS, de Vries TP (2001) Teacher's guide to good prescribing. WHO, Geneva

3. Richir MC, Tichelaar J, Geijteman ECT, de Vries TPGM (2008) Teaching clinical phamacology and therapeutics with emphasis on the therapeutic reasoning of undergraduate medical students. Eur J Clin Pharmacol 64(2):217-224

4. Hogerzeil H (2012) Note for the Record. WHO, Geneva

5. de Vries TP, Henning RH, Hogerzeil HV, Bapna JS, Bero L, Kafle KK, Af M, Santoso B, Smith AJ (1995) Impact of a short course in pharmacotherapy for undergraduate medical students: an international randomised controlled study. Lancet 346(8988):1454-1457

6. De Vries TP (1993) Presenting clinical pharmacology and therapeutics: evaluation of a problem based approach for choosing drug treatments. Br J Clin Pharmacol 35(6):591-597

7. Kamarudin G, Penm J, Chaar B et al (2013) Educational interventions to improve prescribing competency: a systematic review. BMJ Open 3:e003291

8. Ross S, Loke YK (2009) Do educational interventions improve prescribing by medical students and junior doctors? A systematic review. Br J Clin Pharmacol 67:662-670

9. Smith A, Hill S, Walkom E et al (2005) An evaluation of the World Health Organization problem-based pharmacotherapy teaching courses (based on the "Guide to Good Prescribing") 1994-2001. Eur J Clin Pharmacol 61:785

10. Brinkman DJ, Tichelaar J, Okorie M, Bissell L, Christiaens T, Likic R, Mačiulaitis R, Costa J, Sanz EJ, Tamba BI, Maxwell SR, Richir $\mathrm{MC}$, Van Agtmael MA, education working Group of the European Association for clinical pharmacology and therapeutics (EACPT) (2017) Pharmacology and therapeutics education in the European Union needs harmonization and modernization: a cross-sectional survey among 185 medical schools in 27 countries. Clin Pharmacol Ther 102(5):815-822

11. Keijsers CJ, de Wit JE, Tichelaar J, Brouwers JR, de Wildt DJ, de Vries TPGM, Jansen PA (2015) Education on prescribing for older patients in the Netherlands: a curriculum mapping. Eur J Clin Pharmacol 71(5):603-609

12. Kramers C, Janssen BJ, Knol W, Hessel MH, Mulder WM, Dumont G, Maassen van den Brink A, Tichelaar J (2017) A Licence to prescribe. Br J Clin Pharmacol 83(8):1860-1861. https://doi.org/ 10.1111/bcp.13257

13. Jansen DRM, Keijsers CJPW, Kornelissen MO, Olde Rikkert MGM, Kramers C; (on behalf of the education working group of the Dutch Society for Clinical Pharmacology and Biopharmacy) (2019) Towards a "prescribing license" for medical students: development and quality evaluation of an assessment for safe prescribing. Eur J Clin Pharmacol 75(9):1261-1268. https://doi.org/10. 1007/s00228-019-02686-1

14. Maxwell SRJ, Cameron IT, Webb DJ (2015) Prescribing safety: ensuring that new graduates are prepared. Lancet. 385(9968):579581. https://doi.org/10.1016/S0140-6736(14)62339-4

15. Maxwell SRJ, Coleman JJ, Bollington L, Taylor C, Webb DJ (2017 Oct) Prescribing safety assessment 2016: delivery of a national prescribing assessment to 7343 UK final-year medical students. Br J Clin Pharmacol 83(10):2249-2258. https://doi.org/10.1111/ bcp. 13319

16. Smith A, Tasioulas T, Cockayne N, Misan G, Walker G, Quick G (2006) Construction and evaluation of a web-based interactive prescribing curriculum for senior medical students. Br J Clin Pharmacol 62(6):653-659 
17. Bordman R, Bajcar J, Kennie N, Fernandes L, Iglar K (2013) Curriculum to enhance pharmacotherapeutic knowledge in family medicine: interprofessional coteaching and web-based learning. Can Fam Physician 59(11):e493-e498

18. Sanz E, Puerta E (2017) "Pdrugsapp": a mobile app for implementing the WHO guide to good prescribing by medical students. Clin Ther 39(8):91-92

19. Akici A, Kalaca S, Ugurlu MU et al (2003) Impact of a short postgraduate course in rational pharmacotherapy for general practitioners. Br J Clin Pharmacol 57:310-321

20. Coles C (1998) How students learn: the process of learning. In: Jolly B, Rees L (eds) Medical education in the millennium. Oxford University Press, Oxford, pp 63-82

21. Schutte T, Tichelaar J, van Agtmael MA (2016) Learning to prescribe in a student-run clinic. Med Teach 38(4):425

22. Schutte T, Tichelaar J, Donker E, Richir MC, Westerman M, van Agtmael MA (2018) Clarifying learning experiences in student-run clinics: a qualitative study. BMC Med Educ 18(1):244

23. Dekker RS, Schutte T, Tichelaar J, Thijs A, van Agtmael MA, de Vries TP, Richir MC (2015) A novel approach to teaching pharmacotherapeutics - feasibility of the learner-centered studentrun clinic. Eur J Clin Pharmacol 71(11):1381-1387

24. Schutte T, Tichelaar J, Dekker RS, Thijs A, de Vries TP, Kusurkar RA, Richir MC, van Agtmael MA (2017) Motivation and competence of participants in a learner-centered student-run clinic: an exploratory pilot study. BMC Med Educ. 17(1):23

25. Tichelaar J (2016). Making better prescribers during a contextbased pharmacotherapy learning programme: new insights into the improvement of a pharmacotherapy context-learning programme. (doctoral dissertation. Amsterdam VU). Retrieved from http://dare.ubvu.vu.nl/handle/1871/54827

26. Carroll AE (2019) Averting alert fatigue to prevent adverse drug reactions. JAMA. 322(7):601

27. Bakkum MJ, Tichelaar J, Wellink A et al (2019) Digital learning to improve safe and effective prescribing: a systematic review. Clin Pharmacol Ther. https://oi.org/10.1002/cpt.1549 Review

28. Brinkman DJ, Tichelaar J, Schutte T, Benemei S, Böttiger Y, Chamontin B, Christiaens T, Likic R, Mačiulaitis R, Marandi T, Monteiro EC, Papaioannidou P, Pers YM, Pontes C, Raskovic A, Regenthal R, Sanz EJ, Tamba BI, Wilson K, de Vries TP, Richir MC, Van Agtmael MA, working group research on CPT education of the EACPT (2017) Essential competencies in prescribing: a first
European cross-sectional study among 895 final-year medical students. Clin Pharmacol Ther 101(2):281-289

29. Elwyn G, Frosch D, Thomson R, Joseph-Williams N, Lloyd A, Kinnersley P, Cording E, Tomson D, Dodd C, Rollnick S, Edwards A, Barry M (2012) Shared decision making: a model for clinical practice. J Gen Intern Med 27(10):1361-1367 Review

30. WHO Medicines (2019) Vaccines and pharmaceuticals (MVP) 2018 annual report: promoting access to safe, effective, quality and affordable essential medical products for all (WHO/MVP/ EMP/2019.03). World Health Organization, Geneva Licence: CC BY-NC-SA 3.0 IGO

31. Coleman JJ, Samer C, Zeitlinger M, van Agtmael M, Rongen GA, Marquet P, Simon T, Singer D, Manolopoulos VG, Böttiger Y (2019) The European Association for Clinical Pharmacology and Therapeutics -25 years' young and going strong. Eur J Clin Pharmacol 75(6):743-750

32. Brinkman DJ, Tichelaar J, Mokkink LB, Christiaens T, Likic R, Maciulaitis R, Costa J, Sanz EJ, Maxwell SJR, Richir MC, van Agtmael MA (2018) Education working Group of the European Association for clinical pharmacology and therapeutics (EACPT) and its affiliated network of teachers in pharmacotherapy (NOTIP). Key learning outcomes for clinical pharmacology and therapeutics education in Europe: a modified Delphi study. Clin Pharmacol Ther 104(2):317-325

33. van der Voort T, Brinkman DJ, Benemei S, Böttiger Y, Chamontin B, Christiaens T, Likic R, Mačiulaitis R, Marandi T, Monteiro EC, Papaioannidou P, Pers YM, Pontes C, Raskovic A, Regenthal R, Sanz EJ, Wilson K, Tichelaar J, van Agtmael MA, Working Group Research on CPT Education of the European Association for Clinical Pharmacology and Therapeutics (EACPT) (2019) Appropriate antibiotic prescribing among final-year medical students in Europe. Int J Antimicrob Agents 54(3):375-379. https:// doi.org/10.1016/j.ijantimicag.2019.05.008

34. Denig P, Haaijer-Ruskamp FM, Zijsling DH (1988) How physicians choose drugs. Soc Sci Med 27(12):1381-1386

35. Bissessur SW, Geijteman ECT, Al-Dulaimy M, Teunissen PW, Richir MC, Arnold AER, Vries TPGM d (2009) Therapeutic reasoning: from hiatus to hypothetical model. J Eval Clin Pract 15(6): 985-989

Publisher's note Springer Nature remains neutral with regard to jurisdictional claims in published maps and institutional affiliations. 